\title{
sciendo
}

\section{The value of knowledge management in cultural entrepreneurship}

\author{
Alexandra ZBUCHEA \\ National University of Political Studies and Public Administration, Bucharest, Romania \\ alexandra.zbuchea@facultateademanagement.ro
}

\begin{abstract}
Although the concept seems to be self-explanatory and increasingly more people with various artistic talents or a special interest in arts \& culture endeavor themselves in various business-like activities, while culture is praised increasingly more as a key towards sustainable development of the contemporary society, cultural entrepreneurship is not a familiar presence in the academic inquiries. The main associations considered when talking about cultural entrepreneurship are the ones with talent, creativity, cultural innovation. Another aspect analyzed by the literature is the relationship to financial education and skills. The relevance of all these elements is obvious. Maybe less straightforward is the need for knowledge management in the field of cultural entrepreneurship since talent and culture are in many contexts considered apart from knowledge. Nevertheless, knowledge management should be a sinequa-non component of the business strategy of a cultural entrepreneur considering the competitive advantages it could generate. To unveil the known relationships between knowledge management and cultural entrepreneurship, the present research develops a narrative literature review. The results point out the limited understanding of cultural entrepreneurship, including the role knowledge management might play in cultural enterprises.
\end{abstract}

Keywords: Cultural entrepreneurship, cultural entrepreneur, creative entrepreneurship, knowledge management, knowledge transfer.

\section{Introduction}

Although extremely important for the well-being of contemporary society, from an economic perspective culture and culture-related businesses are included in a wider concept of (cultural and) creative industries. This larger group includes besides culture, arts, performing arts, domains such as architecture, music and film industries, book market, media, as well as the software and games industry.

The economic relevance of culture and has been presented in several studies, highlighting that cultural entrepreneurship is a path for sustainable development if a society (Nurse, 2006; Roders, \& van Oers, 2011; Vlassis, 2016). Culture could support sustainable growth for developing countries, but the inadequate development of the associated infrastructure and capabilities and financial resources pose significant challenges (Toghraee\&Monjezi, 2017). Most studies investigating the role of culture, including its economic relevance, concentrate on heritage and large-scale cultural organizations. Cultural enterprises could have a wider impact, not only on their beneficiaries or employees. As Zbuchea and Romanelli (2018) investigated, even small cultural entrepreneurial initiatives could have a wider social, economic and urban impact, even if they are not large-scale and finance-intensive endeavors, such as the famous cases of Guggenheim Museum in Bilbao, Tate St. Ives or the Bayreuth festival, for instance.

Therefore, the theme is very complex. Previous literature reviews (Dobreva\&Ivanov, 2020; Mazzoni\&Lazzeretti, 2018) show that knowledge - although relevant for any cultural endeavor is not a concern for researchers, except as information and new technologies. But the latter aspects are considered only from the perspective of their impact on business models, not asfacilitators of knowledge (Dobreva\&Ivanov, 2020). Mazzoni and Lazzeretti (2018) develop a literature review that confirms that the investigations on cultural entrepreneurship are limited, 
despite an increase both in number and interdisciplinary approaches. In this poor research context, the present paper aims to shed light on what we already know about knowledge management in cultural enterprises.

\section{Cultural entrepreneurship - navigating unclear waters}

Lounsbury and Glynn (2019) show that the interest in cultural entrepreneurship is relatively new, the first academic concerns dating from the early ' $80 \mathrm{~s}$. In a quite fast pace, the interest shifted from elite/high culture towards mass-produces and mass-consumed cultural products. Therefore, we observe that the concept refers to a wide variety of initiatives and organizations. The concept of cultural entrepreneurship is sometimes not related to a business connected to cultural sector, designating the use of culture in entrepreneurial narratives, to better communicate and interact with various publics (Holt \& Macpherson, 2010).

A brief relevant definition of the concept is difficult to pinpoint. We will highlight some of the previous efforts in this vein, centralized in Table 1.

Table 1. Defining cultural entrepreneurship

\begin{tabular}{|c|c|c|}
\hline Author(s) & Definition & Key aspects \\
\hline $\begin{array}{l}\text { DiMmaggio, } \\
1986\end{array}$ & $\begin{array}{l}\text { all forms of entrepreneurial action are } \\
\text { fundamental constituted by similar kinds of } \\
\text { cultural processes. }\end{array}$ & Inner-orientation \\
\hline $\begin{array}{l}\text { Lounsbuty\& } \\
\text { Glynn, } 2001\end{array}$ & $\begin{array}{l}\text { the process by which actors draw upon cultural } \\
\text { resources (e.g., discourse, language, } \\
\text { categories, logics, and other symbolic } \\
\text { elements) to advance entrepreneurship or to } \\
\text { facilitate organizational or institutional } \\
\text { innovation }\end{array}$ & Inner-orientation \\
\hline $\begin{array}{l}\text { Swedberg, } \\
2006\end{array}$ & $\begin{array}{l}\text { combining artistic components (e.g., a set of } \\
\text { paintings) and economic components (e.g., } \\
\text { marketing) differently } \\
\text { the carrying out of a novel combination that } \\
\text { results in something new and appreciated } \\
\text { in the cultural sphere }\end{array}$ & $\begin{array}{l}\text { Inner-orientation } \\
\text { Outer-orientation }\end{array}$ \\
\hline $\begin{array}{l}\text { Wilson \& } \\
\text { Stokes, } 2006 \\
\end{array}$ & $\begin{array}{l}\text { Creating creative ideas and pursuing them } \\
\text { within business path for profitability }\end{array}$ & Inner-orientation \\
\hline Johnson, 2007 & $\begin{array}{l}\text { Refers both to the creativity and initiative of } \\
\text { the founder and to the constraint and } \\
\text { opportunity represented by the specific cultural } \\
\text { schemas that structure the historical context in } \\
\text { which the founder is embedded }\end{array}$ & $\begin{array}{l}\text { Both inner- and } \\
\text { outer-orientation }\end{array}$ \\
\hline Philips, 2011 & $\begin{array}{l}\text { the process whereby tangible cultural capital is } \\
\text { created }\end{array}$ & $\begin{array}{l}\text { Inner-orientation for } \\
\text { public benefit }\end{array}$ \\
\hline $\begin{array}{l}\text { Chang and } \\
\text { Wyszomirski, } \\
2015\end{array}$ & $\begin{array}{l}\text { a management process through which cultural } \\
\text { workers seek to support their creativity and } \\
\text { autonomy, advance their capacity for } \\
\text { adaptability and create artistic as well as } \\
\text { economic and social value. }\end{array}$ & $\begin{array}{l}\text { Both inner- and } \\
\text { outer-orientation }\end{array}$ \\
\hline Suwala, 2015 & $\begin{array}{l}\text { (also referred to as culturepreneurship or art } \\
\text { entrepreneurship) characterizes a sphere of } \\
\text { activities with subject to constant change } \\
\text { between once unconnected fields of the arts, }\end{array}$ & $\begin{array}{l}\text { Both inner- and } \\
\text { outer-orientation }\end{array}$ \\
\hline
\end{tabular}




\begin{tabular}{|l|l|l|}
\hline & the cultural and business sector & \\
\hline $\begin{array}{l}\text { Herrmann- } \\
\text { Feng, 2017 and }\end{array}$ & $\begin{array}{l}\text { the various activities of sense-making and } \\
\text { cultural creativity in the economic domain, } \\
\text { which relate to the existing embodiments of } \\
\text { culture in the larger context of a given society }\end{array}$ & Outer-orientation \\
\hline $\begin{array}{l}\text { Dobreva } \\
\text { andIvanov, }\end{array} 2020$ & $\begin{array}{l}\text { specific activity of establishing cultural } \\
\text { businesses and bringing to market cultural and } \\
\text { creative products and services that encompass } \\
\text { a cultural value but have also the potential to } \\
\text { generate financial revenues }\end{array}$ & Outer-orientation \\
\hline
\end{tabular}

PICBE | 638

Source: Author's research.

All these definitions highlight that the concept encompasses a wide range of entrepreneurial endeavors, but in many cases, arts are the main concerns. Some of the definitions are stressing the organizational aspects being concerned more in the inner processes of organizationa. Some of them focus on outer-environment and impact. Although Table 1 does not present an exhaustive review of the definitions, it suggests a shift in time from the inner- to the outer-perspective. This approach, accepted by the cultural entrepreneurs, might give them a competitive advantage, because it helps them have a marketing perspective on their business and create a more relevant value for the society, therefore benefit from a higher level of recognition and more economic success.

Another evolution relevant to the field of cultural entrepreneurship is the integration of the internet. Some researchers argue that the internet generated a "second wave" of cultural entrepreneurship offering new opportunities (Oakley, p.147).

Gehman and Soublière (2017) show that there are three distinct perspectives: cultural entrepreneurship as making culture, as deploying cultural and as cultural making. The aim of these entrepreneurial endeavors is not primarily economic, but rather creative, and innovation has an important role (Toghraee\&Monjezi, 2017). Cultural entrepreneurship has a cultural intrinsic value, which is purposefully aimed by the entrepreneur, as well as an instrumental value associated with the economic dimension of the endeavor (such as various tangible items, job creation, wealth distribution, etc. - see Toghraee\&Monjezi, 2017). This later aspect determines the concrete contribution of cultural entrepreneurship to local development, but they are not purposefully considered in many cultural entrepreneurial situations.

The previous succinct ideas show the complexity of the cultural entrepreneurship, which could manifest in many ways. Essig (2017) points out not only the evolution depending on the historical context but also the cultural diversity of understandings and approaches associated with cultural entrepreneurship.

Cultural entrepreneurship is seen as a combination of three components: cultural mission and enthusiasm, external trend focusing on innovation, and social accountability based on the critical infrastructure of culture (Toghraee\&Monjezi, 2017, p.6). It also ensures a balancebetween the creative, functional, and productive component of the business (Suwala, 2015). The prevalence of the latter component ensures the market success, but all three components contribute to the sustainability of the endeavor.

Another common trait of cultural entrepreneurship endeavors is the lack of economic capital (Scott, 2012). This generates additional risks, as well as the substitution of the capital with other 
assets, networks being an option. One strategy that cultural entrepreneurs adopt to strive is creating symbolic capital, defining themselves as a subject of value (Scott, 2012).

Many definitions concentrate on the culture-related traits of the entrepreneur- an artist, a person with strong cultural values (see also Suwala, 2015). Researchers define frequently the concept of cultural entrepreneurship through that of a cultural entrepreneur (See Toghraee\&Monjezi, 2017, p.3, or Hausmann\&Heinze, 2016). The cultural entrepreneurs are seen by Hausmass (2010) as artists undertaking business activities within one of the four traditional, and by sectors of the arts [...]. [They] discover and evaluate opportunities in the arts and leisure markets and create a (micro)business to pursue them; or by Scott (2012, p.251) as youthful agents who adopt entrepreneurial dispositions to generate cultural products while reproducing their labourpower through flexible labour markets, notably the expanding service sector. These understandings stress the external pressure that these persons face, as well as the dependence on the market in the field of culture and the arts - which have strong personal dimensions. Kavousy et al. (2010) define cultural entrepreneurs as resourceful visionaries, generating revenues from culturally embedded knowledge systems and activities; their innovative applications of traditions to markets result in economically sustainable cultural enterprises. This perspective highlights the importance of knowledge and knowledge management for cultural entrepreneurs and their businesses.

Entrepreneurial initiatives depend both on the external conditions, such as economic situation, business opportunities, the existence of incubators, policies, cultural factors and others (Del Bosco et al., 2019; Liñán, Rodríguez-Cohard, \& Rueda-Cantuche, 2011), but also on the personal characteristics of the entrepreneurs. Entrepreneurial endeavors are dependent on the figure of the entrepreneur(s). $\mathrm{S} /$ he is the one with the vision and the ability to move the business forward. The cultural entrepreneur is seen as a person who encompasses pioneer spirit, is risk-taking, and almost plainly obsessed to accomplish objectives of self-fulfillment, independence and propensity (Suwala, 2015). These are general traits of entrepreneurs. Additionally, cultural entrepreneurs are at the same time either artists themselves or have strong cultural values. Suwala (2015) observes that What distinguishes cultural entrepreneurs, from artists, performers or curators, is their focus on abilities to valorize novel cultural ideas, methods or artifacts, often originating from third parties (e.g. these same artists, performers, and practitioners) on the one hand. A certain degree of meaningful novelty, however, must be assured, a pure duplication (e.g. mass copying of CDs is the domain of cultural managers) or arbitrage-based value creation (e.g. buy at lower and selling at higher prices, art dealers) is not sufficient on the other hand.

Some other peculiarities of cultural entrepreneurs are flexibility, multi-skilled, psychological resilient (Scott, 2007, p.242), but they differentiate themselves from other entrepreneurs in several ways (Marinova\&Borza, 2013; Klamer, 2011; Oakley, 2013). Nevertheless, their behavior is not related only to their characteristics and personal drives, but also to the economic, social, and cultural frameworks in which they operate (Sardana, 2015). In these contexts, the transfer of knowledge from and towards cultural entrepreneurs are influencing their activity in a significant way (Zbuchea\& Leon, 2015).

In the case of cultural entrepreneurship, especially in developing countries, there is a gap between cultural values and capabilities on one hand, and the economic dimension and entrepreneurial understanding on the other hand (Toghraee\&Monjezi, 2017). Probably in most cases, the motives for cultural entrepreneurial initiatives lies with the cultural dimension. This 
inner conflict might be one of the main causes of the relatively small growth of many cultural businesses.

When considering the cultural entrepreneurship, the figure of the entrepreneur, who could be an artist, is paramount. Not only her/his cultural values and profile are important, but also her/his managerial and economic vision and capabilities are crucial. There are some of the aspects that determine that, in many situations, the cultural entrepreneurial endeavors are small businesses (Phillips, 2011; Oakley, 2013, p.148). Also, the central figure of the cultural entrepreneur determines the establishment and operation of a stable network supporting the activities of the business (Ponzini, 2010). Knowledge transfer within this permanent network might determine its sustainability.

\section{Methodology}

Dobreva and Ivanov (2020) have recently developed a structured literature review identifying eight domains of interest for the researchers in cultural entrepreneurship: 'Characteristics and motivation of entrepreneurs', 'Business models', 'Audiencedevelopment', 'Use of information and communication technologies', 'Urban development', 'Public policy', 'Incubators and clusters' and 'Entrepreneurial education'. The investigated studies reveal the increased importance of the cultural entrepreneur within contemporary society and the economy. This stresses the need to better understand this sector, as well as cultural entrepreneurs. Among these aspects, understanding of knowledge management (KM) in cultural enterprises would lead to increased effectiveness. The present study proposes a narrative literature review aiming to highlight what we know about knowledge management in cultural enterprises.

A narrative literature review (Green, Johnson, \& Adams, 2006) synthesizing the findings of literature retrieved from academic databases, drawing a picture of the current state-of-the-art. If properly developed it could lead to an objective overview of the state of research. This aim is difficult to achieve since it is a non-systematic endeavor and there are no set guidelines and subjectivity is a main concern (Ferrari, 2015). A narrative review is used especially for understanding the current (lack of) knowledge, as well as the rationales for future investigation.

The structure of the review we propose is chronological. This allows us to observe the evolution of research interests in the field, both in quantity and in contents. The databased used consist of some of the main academic databases: Clarivate Analytics and Sciendo. The first one offers top-quality studies but limits the research by excluding studies that may be considered at a time of secondary relevance, such as in the case of the domain considered. Critics (Lariviere\& Sugimoto, 2018) consider various technical as well as interpretative debatable aspects. Nevertheless, the studies included in Clarivate Analytics are more influential, generally speaking, than other studies. To have a more inclusive body of articles, considering the relatively narrow field of investigation, we extended the search to Sciendo, a growing and, therefore, increasingly more influential academic platform.

The keywords considered are KM and cultural entrepreneurship, as well as KM and arts entrepreneurship. Since research tends to discuss the cultural entrepreneur this keyword was also considered, connected to knowledge management. The alternative of culturepreneur was also a keyword.Also, knowledge transfersand networking were used since they areamong the main considered aspects of knowledge management, and previous studies showtheir relevance tothe cultural field (Zbuchea\& Leon, 2015). Intellectual capital was another substitute used for KM. 
The first round of searches determined only 9 items; therefore, the search has been extended using the general term of "knowledge" instead of "knowledge management". The final entries obtained was of 35 articles for WoS and 10 articles for Sciendo. After eliminating the duplicates and unrelated studies, the corpus consists of 9 published studies.

\section{Results and discussions}

PICBE | 641

The search revealed a limited number of studies, showing the low visibility of this topic in the main academic research. 2 of the 9entries identified have been published in Sciendo. All the articles have been published in the past 10 years, showing a very recent interest in the topic.Figures 1 and 2 show the structure of the article sample.

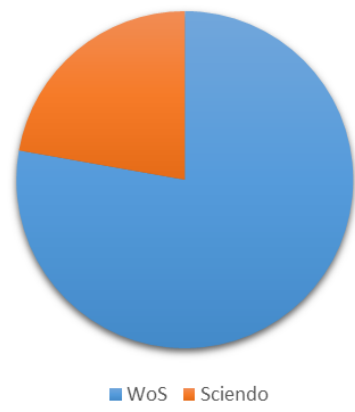

Figure 1. Structure of the sample, considering the database

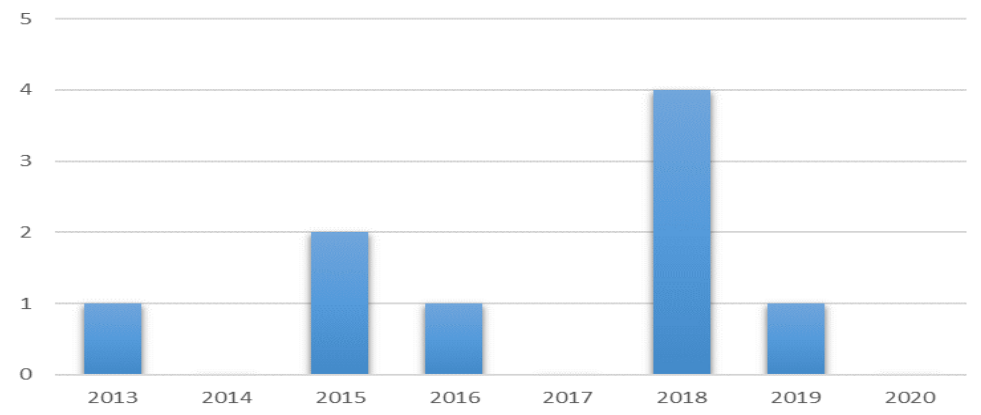

Figure 2. Structure of the sample, considering the year of publication

Searching the two databases only using "cultural entrepreneurship" revealed more than 200 entries on Web of Knowledge and 9 items for Sciendo. The above findings show an extremely limited body of knowledge on knowledge management in cultural entrepreneurship, therefore there is a wide gap to be filled. Except for an Australian study, all the others have been developed in Europe (Germany, Romania, Latvia, Spain, the Netherlands, Greece, and Portugal). Almost half of the articles are quantitative investigations. To map the knowledge we already have, we present in chronological order the identified articles.

The oldest identified article, published in 2013, deals with knowledge management collaterally. It investigates the social network relationships' impact on cultural organizations (Konrad, 2013). The analysis shows the main role they play not only for organizational development but also in the establishing of a cultural enterprise. The research also reveals that lower the competition as well as sponsorship opportunities, the stronger the impact of networking.

The importance of networking is also documented by the study of Zbuchea and Leon (2015).This is one of the few articles in our corpus that specifically investigates knowledge management aspects, more exactly knowledge transfer within and outside cultural organizations (except one, all the interviewed organizations are nonprofits). The main concerns identified are access to knowledge and formal knowledge sharing. In both situations, the internet is key to these processes. The study shows a general concern with cognitive knowledge, as well as the relevance of personal factors and networking on knowledge sharing. 
Saskia de Klerk (2015) investigates how cultural and creative entrepreneurs combine resources to solve problems and valorize opportunities, called entrepreneurial bricolage. This is a relevant topic for social entrepreneurs, which face a lack of resources, including knowledge. The author shows that in creative industry collaborative bricolage based on projects comes naturally. The study confirms that resources are a main concern, and access to them determines cultural entrepreneurs to take financial, reputational, and personal risk. Networking is seen as an opportunity to cope with the lack of resources. The challenge is to find a balance between competing and working with peers. Another dimension of collaboration is access to information and know-how. Mentoring and inspiring others are important drives for collaboration. Networking is therefore beneficial in cultural entrepreneurship and is connected to a competecollaborate-create environment.

Many studies show the importance of stakeholders for cultural organizations, including business. Zemite (2016) shows their role in the evaluation of cultural enterprises. The cultural managers which show a appreciate cooperation, also positively evaluate the engagement of stakeholders and ensure long-term relationships. These could also contribute to knowledge transfer, but this dimension has not specifically been investigated. The study documents a positive impact on efficiency from information on the internet environment and the public sphere - and this knowledge could be influenced by stakeholders' engagement. They also influence the process of creating and disseminating artistic value. This study suggests that stakeholders could be subject to the strategies of knowledge management, at least in the context of knowledge transfer both online and offline, but they could also be part of knowledge creation processes. The research also reveals that managers focused on artistic performance tend to disregard the cooperation with stakeholders, especially if this cooperation has not been validated in the longterm. In this context, knowledge sharing and networking strategies might be limited.

Another article investigated the power of networking (Mylonas\&Petridou, 2018). Professional networking, besides creativity, is an important factor to ensure venture performance in cultural entrepreneurship.The third one is the entrepreneurial orientation. The study has been developed only among women entrepreneurs, but other studies also confirm that networking is important for all cultural entrepreneurs.

Innovation transfer and strategies of cultural entrepreneurs to enhance economic, cultural, and social value are investigated by Petrova (2018). Knowledge spillover is a way to acquire information and exchange ideas in the sector. Transfer of innovation in the cultural sector might be facilitated by its mobility as well as by a specific sense of belonging and shared values. Multistakeholder collaborations facilitate knowledge sharing, both formal and tacit. Knowledge spillover from cultural endeavors could lead to innovation transfer and more creative approaches in other sectors too.

Istudor (2018) investigates the innovative dimension of cultural entrepreneurship. She connects innovation with intellectual capital. Romania has a low innovation index, therefore, the intellectual capital is not so competitive. Still, the study reveals that the main concerns of the entrepreneurs in the cultural and creative sector in Romania are related to the legislation and political environments, as well as with the financing of the business. Overall, Romanian entrepreneurs are lagging behind the other European entrepreneurs, therefore more focus and investment in knowledge management would be recommended.

Orihuela-Gallardo, Fernández-Alles, and Ruiz-Navarro (2018) analyze the profile of the characteristics of the cultural entrepreneur on the employment growth and performance of 
cultural businesses. The study reveals the employment growth is negatively influenced by the age of the entrepreneur. The experience has a partial positive impact on growth as well as performance. At the same time, the study documents no direct relationships between resources including knowledge - and performance. This might be unexpected. A cultural entrepreneur uses knowledge to create value, but this is not necessarily transformed in the market in profits.

The last article considered investigates crowdfunding aspects related to cultural productions (Foà, 2019). The analysis highlights the important role of experience-led campaigns, shared meaning, and involvement of other actors to ensure the success of crowdfunding. Creating value through the interaction with stakeholders mediates the success of such campaigns. Networks and the transfer of knowledge along their lines are facilitators in this process. The study identifies also that knowledge, skills, and socialcapital as an experientialreward (partnership co-creation) are the main weaknesses of the marketing strategies associated with crowdfunding for culture. A successful campaign should consider that the crowdfunding ecosystem is a complex one and networking with all the members is recommended.

\section{Conclusion}

Although there is a positive understanding of the role of knowledge management in cultural enterprises which could benefit in several ways, the academic research does not consider a complex investigation of the actual practices. This research shows that there is an extremely low interest in the academic environment for knowledge management in cultural organizations even if knowledge is extremely important for creativity and innovation, as well as for entrepreneurial endeavors. This is even more paradoxical considering that previous interviews with cultural entrepreneurs show the high value they place on knowledge and knowledge sharing. The interest of the studies included in the investigated databases is very poor both in terms of quantity and quality. The most frequent topic approached by researchers in networking, including cooperation with stakeholders. The second topic approached is somewhat similar, referring to knowledge sharing. Nevertheless, academic research could be wider, but other studies might lack the visibility and influence of the ones identified.

\section{References}

Chang, W.J., \&Wyszomirski, M. (2015). What is arts entrepreneurship? Tracking the development of its definition in scholarly journals. Artivate: A Journal of Entrepreneurship in the Arts, 4(2), 11-31.

de Klerk, S. (2015). The creative industries: an entrepreneurial bricolage perspective. ManagementDecision. 53(4), 828-842

Del Bosco, B., Mazzucchelli, A., Chierici, R., \& Di Gregorio, A. (2019). Innovative startup creation: the effect of local factors and demographic characteristics of entrepreneurs. International Entrepreneurship and Management Journal, 1-20.

Dobreva, N., \& Ivanov, S. (2020). Cultural entrepreneurship: a review of the literature. SocArXiv Papers. Available at https://osf.io/preprints/socarxiv/wntrx/.

Essig, L. (2017). Same or different? the "Cultural entrepreneurship" and "Arts entrepreneurship" constructs in European and US higher education. Cultural Trends, 26(2), 125-137.

Ferrari, R. (2015). Writing narrative style literature reviews. Medical Writing, 24(4), 230-235. 
Foà, C. (2019). Crowdfunding cultural projects and networking the value creation. Arts and the Market. 9(2), 235-254.

Gehman, J., \& Soublière, J. F. (2017). Cultural entrepreneurship: from making culture to cultural making. Innovation, 19(1), 61-73.

Green, B.N., Johnson, C.D., \& Adams, A. (2006). Writing narrative literature reviews for peerreviewed journals: Secrets of the trade. Journal of Chiropractic Medicine, 5(3), 101-117.

PICBE | 644

Hausmann, A. (2010). German artists between bohemian idealism and entrepreneurial dynamics: Reflections on cultural entrepreneurship and the need for start-up management. International Journal of Arts Management, 12(2), 17-29

Hausmann, A., \&Heinze, A. (2016). Entrepreneurship in the cultural and creative industries: Insights from an emergent field. Artivate: A Journal of Entrepreneurship in the Arts, 5(2), 7-22.

Herrmann-Pillath, C., \& Feng, X. (2017). Cultural entrepreneurship in China. Available online at https://www.researchgate.net/profile/Carsten_Herrmann-

Pillath/publication/319954201_Cultural_Entrepreneurship_in_China/links/59c364920f7e9 b21a82f0ec0/Cultural-Entrepreneurship-in-China.pdf.

Holt, R., \& Macpherson, A. (2010). Sensemaking, rhetoric and the socially competent entrepreneur. International Small Business Journal, 28(1), 20-42.

Johnson, V. (2007). What is organizational imprinting? Cultural entrepreneurship in the founding of the Paris Opera. American Journal of Sociology, 113(1), 97-127.

Kavousy, E., Shahosseini, A., Kiasi, S., \&Ardahaey, F. (2010). Cultural entrepreneurship strategies in Iran. Serbian Journal of Management,5(2), 227-241.

Klamer, A. (2011). Cultural entrepreneurship. Review of Austrian Economics, 24(2), 141-156.

Konrad, E.D. (2013). Cultural entrepreneurship: The impact of social networking on success.Creativity and Innovation Management, 22(3), 307-319.

Lariviere, V., \& Sugimoto, C.R. (2018). The journal impact factor: A brief history, critique, and discussion of adverse effects. arXiv preprint arXiv:1801.08992.

Liñán, F., Rodríguez-Cohard, J. C., \& Rueda-Cantuche, J. M. (2011). Factors affecting entrepreneurial intention levels: a role for education. International Entrepreneurship and Management Journal, 7(2), 195-218.

Lounsbury, M., \& Glynn, M. A. (2019). Cultural entrepreneurship: A new agenda for the study of entrepreneurial processes and possibilities. Cambridge University Press.

Marinova, E., \&Borza, A. (2013). The cultural entrepreneurship: creativity and innovation for economic development. Managerial Challenges of the Contemporary Society, 5, 149.

Mazzoni, L., \&Lazzeretti, L. (2018). In search of creative entrepreneurship: an exploratory analysis. In Creative Industries and Entrepreneurship. Edward Elgar Publishing.

Mylonas, N., \&Petridou, E. (2018). Venture performance factors in creative industries: a sample of female entrepreneurs. Gender in Management: An International Journal, 33(5), 385404.

Nurse, K. (2006). Culture as the fourth pillar of sustainable development. Small States: Economic Review and Basic Statistics, 11, 28-40.

Oakley, K. (2013). Good work? Rethinking cultural entrepreneurship. In Handbook of management and creativity. Edward Elgar Publishing. 
Orihuela-Gallardo, F., Fernández-Alles, M., \& Ruiz-Navarro, J. (2018). The influence of the cultural entrepreneur on the performance of cultural and creative firms. Academia Revista Latinoamericana de Administración.

Petrova, L. (2018). Cultural Entrepreneurship in the Context of Spillovers Within the Cultural and Creative Industries. In Entrepreneurship in Culture and Creative Industries (pp. 197211), Cham: Springer.

PICBE | 645

Phillips, R. (2011) Arts Entrepreneurship and Economic Development: Can Every City be Austintatious. Indianapolis: Now Publishers.

Ponzini, D. (2009). Urban implications of cultural policy networks: The case of the mount Vernon cultural district in Baltimore. Environment and Planning C: Government and Policy, 27(3), 433-450.

Roders, A.P., \& van Oers, R. (2011). Bridging cultural heritage and sustainable development. Journal of Cultural Heritage Management and Sustainable Development, 1(1), 5-14.

Sardana, D. (2015). What facilitates cultural entrepreneurship? A study of Indian cultural entrepreneurs. Journal of Creative Behavior, 52(1), pp.35-51

Scott, M. (2012). Cultural entrepreneurs, cultural entrepreneurship: Music producers mobilising and converting Bourdieu's alternative capitals. Poetics, 40(3), 237-255.

Sinapi, C., \& Ballereau, V. (2016). Looking for new sustainable business model in cultural entrepreneurship. Cultural Management Education in Risk Societies-Towards a Paradigm and Policy Shift?!, 336.

Suwala, L. (2015). Cultural entrepreneurship. In F. F. Wherry \& J. B. Schor (Eds.), Encyclopedia of Economics and Society (pp. 513-515). Los Angeles: Sage.

Swedberg, R. (2006). On teasing out sociology from economics: A brief note on Parsons and Schumpeter. American Journal of Economics and Sociology, 65(1), 71-78.

Toghraee, M. T., \& Monjezi, M. (2017). Introduction to cultural entrepreneurship: Cultural entrepreneurship in developing countries. International Review of Management and Marketing, 7(4), 67-73.

Vlassis, A. (2016). UNESCO, cultural industries and the international development agenda: between modest recognition and reluctance. In Contemporary Perspectives on Art and International Development (pp. 68-83). Routledge.

Wilson, N., Stokes, D. (2006), Managing creativity and innovation: The challenge for cultural entrepreneurs. Journal of Small Business and Enterprise Development, 12(3), 366-378.

Zbuchea, A., \& Leon, R. (2015). Knowledge sharing barriers in cultural organizations. Culture, Innovation and Entrepreneurship: connecting the knowledge dots. In Proceedings of IFKAD (pp.1716-1727).

Zbuchea, A., \&Romanelli, M. (2018). The Role of NGOs in Urban Development. In Proceedings of the IFKAD 2018. Societal Impact of Knowledge and Design(pp.637-648).

Zemite, I. (2016). The Role of Stakeholders in Cultural Entrepreneurship Management. Economics and Culture,13(1), 97-103. 